\title{
Electro-Thermal Modelling and Experimental Verification of Power Semiconductor Diode
}

\author{
Miroslav Pavelek, Michal Frivaldsky*, Peter Sojka, Jan Morgos \\ Department of Mechatronics and Electronics, University of Zilina, \\ Univerzitna 8215/1, 01026 Zilina, Slovakia \\ michal.frivaldksy@feit.uniza.sk
}

\begin{abstract}
The aim of the proposed paper is discussing problematics related to the thermal modelling of power electronic components. More in detail, the electro-thermal relationship is investigated for the selected power diode, while analysis shall serve for system optimization considering thermal performance with the use of highly accurate 3D simulation model. The presented approach describes the procedure of the simulation model development, whereby the main part is discussing necessities relevant for material property identification through the indirect procedure, i.e, material properties are not known from the manufacturer. Electrothermal dependencies are defined within the proposed model, while this model enables parametric changes of the geometrical properties of the device. Added value of this procedure is the possibility of its use in exact determination of the lifetime of a semiconductor component using mathematical models taking into account operational variables (current, voltage, temperature, etc.). The proposed model is verified and validated through thermovision experimental measurements within defined operational conditions.
\end{abstract}

Index Terms-Temperature; Modelling; Electro-thermal domain; Power diode; Optimization.

\section{INTRODUCTION}

Thermal management is nowadays one of the key factors targeting reliable operation of any electronic systems. Considering power electronics, this issue is currently relevant as the figure of merit evaluation, because of the continual increase of performance (power density) of semiconductor devices [1]. Speaking about this phenomenon, various packages are currently available on the market and these packages are characterized by different thermal properties. Thermal management is important as a primary issue regarding the lifetime of individual electronic components. Therefore, a precise analysis of thermal performance during the design stage of any electronic system represents an important part of the whole design procedure [2]-[4].

The ways how to proceed within the optimization of the thermal performance are in principle based on experimental measurements or using modern and perspective Finite Element Method (FEM) and Computational Fluid Dynamics

Manuscript received 30 September, 2019; accepted 27 January, 2020.

This research was funded by a grant (No. APVV-15/0396; Project title: "Research of perspective high-frequency converter systems with $\mathrm{GaN}$ technology") from the Slovak National Grant Agency (APVV).
(CFD) analysis tools. Within simulation experimentation, it is possible to tune various parameters related to material properties of internal structural components of devices. However, on the other side, these simulation tools are very useful within the determination of reliable operation of component that is currently available on the market [5], [6]. The simulation of heat exchange processes reduces the potential risks of overheating, allows the creation of products with improved functionality and stability of the working characteristics under high environmental temperature fluctuations, and eliminates the need to create many prototypes until the final design of an electronic device or system has been validated before mass production. Here, the important task is to estimate the component material properties, so to achieve reliable results when compared to experimental measurements [7], [8].

Nowadays, there is a wide spectrum of the experimental instrumentations that enable to precisely identify thermal behaviour of electronic systems. The most reliable and at the same time the most suitable and used is infrared thermography. Even if it seems easy, it is very important to provide experimental measurements within a controlled environment to be able to reliably optimize simulation models based on experimental results. Therefore, it is proposed to secure constant operating conditions like ambient temperature, air humidity, airflow rate, etc. However, this issue requires high demands on laboratory equipment and hardware disposal of the investigated system. For this reason, the exact and reconfigurable simulation model of power semiconductor components represents comfortable way for the pre-design stage of the whole system enabling to eliminate any undesirable behaviour.

The Printed Circuit Board (PCB) design plays also a major role in the thermal control because it provides ways to dissipate the heat generated in the electronic components. Therefore, if a single component is being investigated by simulation, it is required to consider the influences of required subsystems, which influence the component operation [9], [10].

Within the proposed paper, the procedure of electrothermal modelling is provided. It describes the procedure of design of a simulation model of a selected power semiconductor diode. This model considers multi-physics behaviour, i.e. the electrical domain and thermal domain of the analyses. An electrical domain defines operational 
conditions of the component as expected for practical operation (within electronic circuit). Then, based on physics definitions from electrical variables, the variables responsible for thermal performance are identified. Thus, component's thermal behaviour could be evaluated. Within modelling, the subdomains settings are described, together with the definition of geometrical properties of components, as well as material parameters of structural parts. At the end of the paper, the evaluation of simulation model performance is done in the way of comparisons to experimental measurements.

\section{EleCtro-Thermal Model of POWER Diode}

The proposed model of the power diode is created in COMSOL Multiphysics environment as a 3D Model. It uses predefined Multiphysics interface "Joule Heating". Joule heating interface is composed of "Electrical Currents" (EC) physic and "Heat Transfer in Solid" (HTS) physic. The "Semiconductor Physic" is not used in this model because it has higher demands on computing power, but this physic is simulated/replaced by the dependence of the material conductivity on the forward current of the diode. The "Timedependent study" is used in the created model for precise comparison with experimental measurements.

\section{A. Used Physic Interfaces}

The first used physic EC uses a set of equations ((1)-(4)) to compute power losses within the structure:

$$
\begin{gathered}
\nabla \times \boldsymbol{J}=Q_{j}, \\
\boldsymbol{J}=\sigma \boldsymbol{E}+\frac{\partial \boldsymbol{D}}{\partial t}+\boldsymbol{J}_{e}, \\
\boldsymbol{E}=-\nabla V, \\
Q_{e}=\boldsymbol{J} \times \boldsymbol{E},
\end{gathered}
$$

where " $\mathbf{J}$ " is the current density, " $\mathrm{Q}_{\mathrm{j}}$ " is the current source, " $\sigma$ " is the linearized resistivity, "E" is the vector of the electric field, "D" is the vector of electric field displacement, "V" is the electric potential, and "Q $\mathrm{Q}_{\mathrm{e}}$ " is the value of joule losses in given calculation step.

The computed power losses from the EC physic are then used as input values for HTS to calculate the temperature based on (5) and (6):

$$
\begin{gathered}
\rho C_{P} \frac{\partial \boldsymbol{T}}{\partial t}+\rho C_{P} \boldsymbol{u} \times \nabla T+\nabla \times \boldsymbol{q}=Q_{e}+Q_{\text {ted }}, \\
\boldsymbol{q}=-k \nabla T,
\end{gathered}
$$

where " $\rho$ " is the material density, " $\mathrm{C}_{\mathrm{P}}$ " is the specific heat capacity, " $T$ " is the temperature, " $\mathbf{q}$ " is the heat flux, " $\mathbf{u}$ " is the velocity vector, " $\mathrm{Q}_{\mathrm{e}}$ " is the external heat source, " $\mathrm{Q}_{\text {ted" }}$ " is the thermoelastic damping, and " $\mathrm{k}$ " is the thermal conductivity.

The simplified equation used for the electromagnetic heat source can be seen below

$$
\rho C_{P} \frac{\partial \boldsymbol{T}}{\partial t}-\nabla \times(k \nabla T)=Q_{e}
$$

The joule heating interface also uses the output temperature form the HTS as an input in the next calculation step of EC, so the thermal characteristics of the material are respected.

\section{B. Reconfigurable Model of Power Diode}

As it was mentioned before, the created model is a $3 \mathrm{D}$ model and it needed to be reconfigurable in a way of material parameters, as well as geometrical parameters. The model itself is composed of the DIE, the case, the contacts, the pads, and the environment (Fig. 1). The boundary settings for the individual parts of the model are defined in

\begin{tabular}{|c|c|c|c|}
\hline & \multicolumn{3}{|c|}{ Electrical Parameter } \\
\hline Model & \multicolumn{2}{|c|}{$\begin{array}{c}\text { Electrical Conductivity } \\
{[\mathrm{S} / \mathrm{m}]}\end{array}$} & $\begin{array}{c}\text { Relative permittivity } \\
{[-]}\end{array}$ \\
\hline DIE & \multicolumn{2}{|c|}{$\sigma\left(\mathrm{I}_{\mathrm{F}}\right)$ (Fig. 2) } & 11.7 \\
\hline Package & \multicolumn{2}{|l|}{0} & 3.6 \\
\hline Contacts & \multicolumn{2}{|c|}{$5.998 \mathrm{e} 7$} & 1 \\
\hline Pads & \multicolumn{2}{|c|}{$5.998 \mathrm{e} 7$} & 1 \\
\hline Environment & \multicolumn{2}{|l|}{0} & 1 \\
\hline & \multicolumn{3}{|c|}{ Thermal Parameter } \\
\hline Model & $\begin{array}{c}\text { Heat Capacity } \\
{\left[\mathrm{J} /\left(\mathrm{kg}^{\circ} \mathrm{C}\right)\right]} \\
\end{array}$ & $\begin{array}{c}\text { Density } \\
{\left[\mathrm{kg} / \mathrm{m}^{\wedge} 3\right]}\end{array}$ & $\begin{array}{c}\text { Thermal Conductivity } \\
{\left[\mathbf{W} /\left(\mathbf{m}^{\circ} \mathbf{C}\right)\right]}\end{array}$ \\
\hline DIE & 700 & 2329 & 130 \\
\hline Package & 1000 & 1250 & 0.35 \\
\hline Contacts & 385 & 8960 & 400 \\
\hline Pads & 385 & 8960 & 400 \\
\hline Environment & 1000 & 1,839 & 0.026 \\
\hline
\end{tabular}
Table I.

TABLE I. BOUNDARY SETTINGS.

\begin{tabular}{|c|c|c|c|}
\multicolumn{4}{|c|}{ TABLE I. BOUNDARY SETTINGS. } \\
\hline Settings & $\begin{array}{c}\text { Current } \\
\text { Conservation }\end{array}$ & $\begin{array}{c}\text { Electric } \\
\text { Insulation }\end{array}$ & $\begin{array}{c}\text { Initial Electric } \\
\text { Potential }\end{array}$ \\
\hline Model & Yes & No & 0 \\
\hline DIE & Yes & No & 0 \\
\hline Package & Yes & No & 0 \\
\hline Contacts & Yes & No & 0 \\
\hline Pads & Yes & Yes & 0 \\
\hline Environment & \multicolumn{3}{|c|}{ Heat Transfer in Solid } \\
\hline & Solid & Initial Values & $\begin{array}{c}\text { Outflow/Heat } \\
\text { Flux }\end{array}$ \\
\hline Settings & Yes & $25\left[{ }^{\circ} \mathrm{C}\right]$ & No \\
\hline Model & Yes & $25\left[{ }^{\circ} \mathrm{C}\right]$ & No \\
\hline DIE & Yes & $25\left[{ }^{\circ} \mathrm{C}\right]$ & No \\
\hline Package & Yes & $25\left[{ }^{\circ} \mathrm{C}\right]$ & No \\
\hline Contacts & Yes & $25\left[{ }^{\circ} \mathrm{C}\right]$ & Yes \\
\hline Pads & \multicolumn{3}{|c}{} \\
\hline Environment & \multicolumn{3}{|c|}{}
\end{tabular}

The package has material settings of epoxy (Table II) and its geometry is defined by its width "WCASE", length "LCASE", and thickness "TCASE" (Fig. 1).

The contacts (Fig. 1) have material settings of copper (Table II) and their geometry is based on the defined geometry of the die and the package.

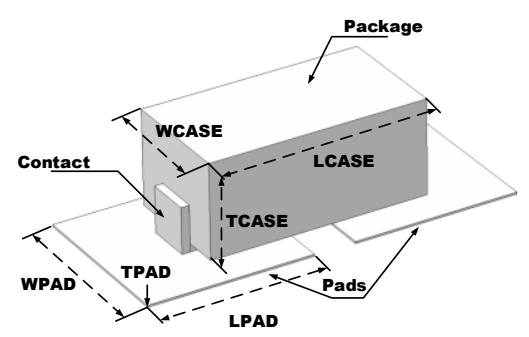

Fig. 1. The proposed model of the power diode. 


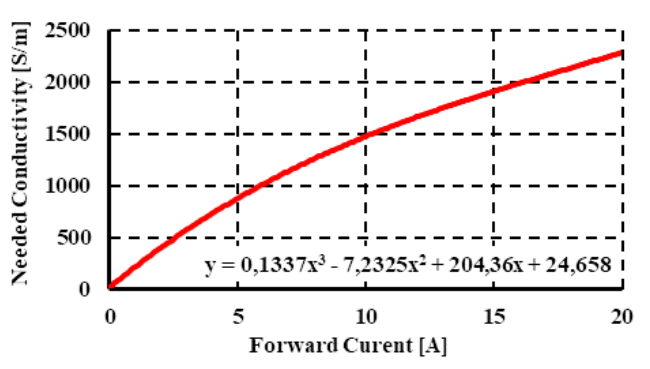

Fig. 2. Needed DIE material dependency of the conductivity at a forward current.

The pads (Fig. 1) have material settings of copper (see Table II) and its geometry is defined by its width "WPAD", length "LPAD", and thickness "TPAD".

The DIE (Fig. 3) has material settings of silicone (see Table II) and its geometry is defined by its width "WDIE", length "LDIE", and thickness "TDIE".

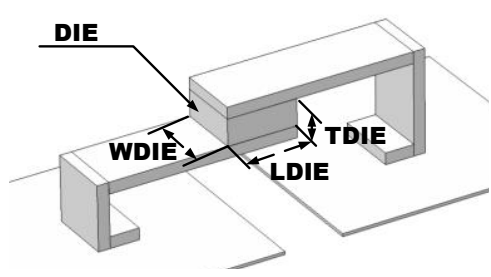

Fig. 3. The DIE with contacts.

\section{Customizing THE MOdEL FOR THE SELECTED Diode}

The customizing of the proposed model to specified power diode is composed form geometry parameters reconfiguration and the DIE conductivity dependency determination. For the verification of the proposed procedure, the power diode "US1MHE3" is used. The geometrical parameters of the package and estimated geometrical parameters of the DIE are presented in Table III. The material parameters are defined in Table II.

TABLE III. GEOMETRICAL PARAMETERS OF "US1MHE3".

\begin{tabular}{|c|c|c|c|}
\hline Model Parameter & Width $[\mathbf{m}]$ & Length $[\mathbf{m}]$ & $\begin{array}{c}\text { Thickness } \\
{[\mathbf{m}]}\end{array}$ \\
\hline DIE & $1.10 \mathrm{e}-3$ & $1.20 \mathrm{e}-3$ & $0.46 \mathrm{e}-3$ \\
\hline Package & $2.79 \mathrm{e}-3$ & $5.28 \mathrm{e}-3$ & $2.29 \mathrm{e}-3$ \\
\hline Pads & $4 \mathrm{e}-3$ & $4 \mathrm{e}-3$ & $50 \mathrm{e}-6$ \\
\hline Environment & $15 \mathrm{e}-3$ & $15 \mathrm{e}-3$ & $15 \mathrm{e}-3$ \\
\hline
\end{tabular}

\section{A. The DIE Conductivity Dependency Determination}

The first step for the needed electrical conductivity dependency determination lies in the determination of the structure conductance with electrical conductivity of the DIE material set to $1 \mathrm{~S} / \mathrm{m}$. The given value of $1 \mathrm{~S} / \mathrm{m}$ is chosen to simplify the further process of the electrical conductivity adaptation of the proposed model. The conductance of the structure acquired this way has the value of $0.0028704 \mathrm{~S}$. In the next step, this value needs to be adapted to structure conductance dependency on diode forward current obtained from datasheet of the given power diode (Fig. 4). The dependency showed on the Fig. 4 can be approximated by third-order polynomial function (8)

$$
\sigma\left(I_{F}\right)_{d s}=0.0004 I_{F}^{3}-0.0208 I_{F}^{2}+0.5866 I_{F}+0.0708
$$

where " $\mathrm{I}_{\mathrm{F}}$ " is forward current of a diode and " $\sigma\left(\mathrm{I}_{\mathrm{F}}\right)_{\mathrm{ds}}$ " is the dependency of the electrical conductivity of the diode structure given by datasheet.

Based on the chosen value of electrical conductivity in the first step $(1 \mathrm{~S} / \mathrm{m})$, the needed dependency of the DIE electrical conductivity (10) is easily obtained based on (9):

$$
\begin{gathered}
\sigma\left(I_{F}\right)=\frac{\sigma\left(I_{F}\right)_{d s}}{0.002874}, \\
\sigma\left(I_{F}\right)=0.1337 I_{F}^{3}-7.2325 I_{F}^{2}+204.36 I_{F}+24.658 .
\end{gathered}
$$

The obtained polynomial function (10) can be then incorporated into the material settings of the created model.

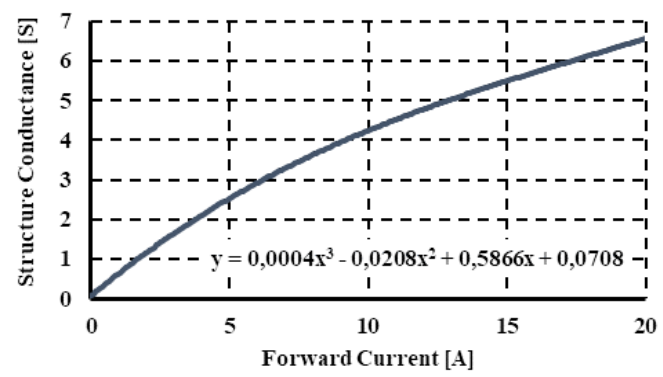

Fig. 4. US1MHE3 power diode conductance to forward current dependency based on the datasheet.

\section{B. The DIE Conductivity Dependency Verification}

The accuracy of the given approach is then given by the comparison of the simulated Volt-Ampere (VA) characteristic with VA characteristic given by the datasheet (Fig. 5). Based on this comparison, we can say that from an electrical point of view the error of the proposed model is less than $5 \%$ in the given range of diode forward current.

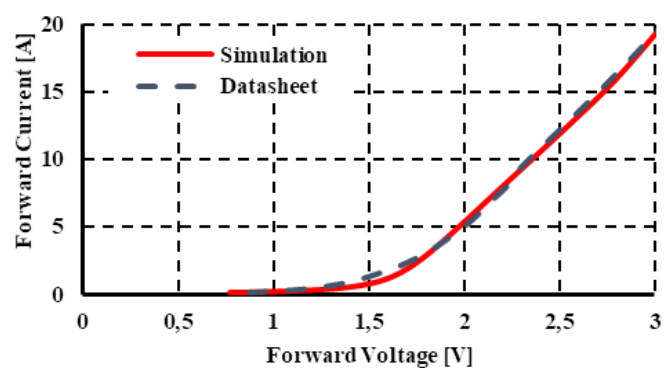

Fig. 5. Comparison of VA characteristics - Simulation and Datasheet.

\section{EXPERIMENTAL MEASUREMENTS AND MODEL EVALUATION}

The experimental measurements have been provided under laboratory conditions. The main electrical parameter, which influences thermal behaviour of the power diode, is the RMS (Root Mean Square) value of the forward current. Due to this fact, experiments have been done in the way to meet thermal modelling procedure, i.e. to accept electrothermal behaviour. Selected power diode was integrated within the circuit of the DC-DC buck converter. Circuit operation was adapted to verify thermal behaviour of the component for the variable RMS value of diode forward current. The values represent the average load current of the component up to its maximum operational limit:

$-\mathrm{I}_{\mathrm{F}(\mathrm{RMS})}=300 \mathrm{~mA}, 400 \mathrm{~mA}, 500 \mathrm{~mA}$. 


\section{A. Measurement Setup and Operating Conditions}

The investigation of operation within experiments have been provided with the boost converter. The investigated diode was connected as a rectifying diode and the voltages and currents were measured. The three different diode currents were set and thermal behaviour of the diode was evaluated with the use of FLIR SC600 thermal camera. The input/output parameters of the converter circuit are listed in Table IV.

The experimental setup is shown on Fig. 6. The diode voltage and current were measured by the current and voltage probe and visualized on the digital oscilloscope. The input and output voltages and currents were measured with precise power analyser.

TABLE IV. MATERIAL PARAMETERS.

\begin{tabular}{|c|c|}
\hline Input converter voltage [V] & 12 \\
\hline Output converter voltage [V] & 24 \\
\hline Input converter current [A] & $0.31,0.42,0.53$ \\
\hline Output converter current $[\mathbf{A}]$ & $0.15,0.2,0.25$ \\
\hline Converter switching frequency [kHz] & 100 \\
\hline Ambient temperature $\left[{ }^{\circ} \mathbf{C}\right]$ & 25 \\
\hline
\end{tabular}

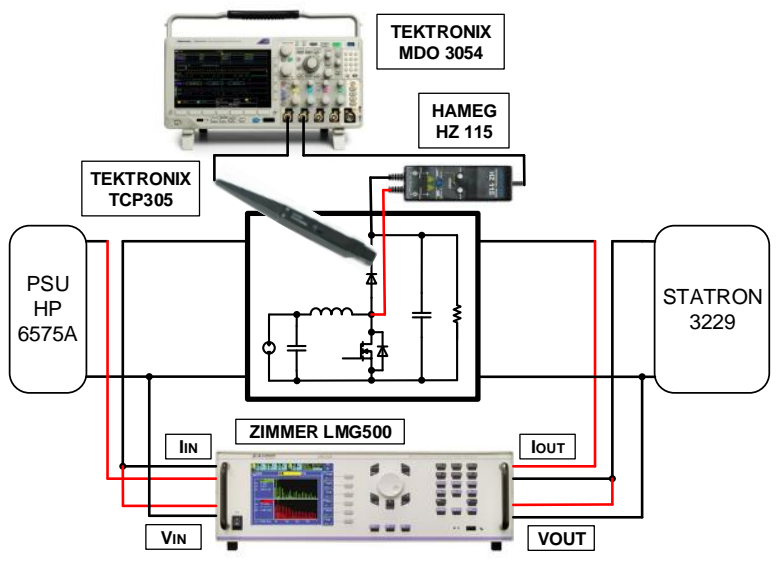

Fig. 6. Experimental set-up for investigation of thermal performance of US1MHE3 within proposed boost converter.

\section{B. Measurement Results}

The experiments have been made based on the experimental set-up described above. The focus was given on infrared thermovision measurements of selected power diode. Figure 7 shows temperature distribution within the surface of investigated component indicating hot spot. This point is located at the space, where a silicon power chip is integrated within the diode package. As can be seen, the maximum temperature for the situation of $\mathrm{I}_{\mathrm{F}(\mathrm{RMS})}=300 \mathrm{~mA}$ has reached $120^{\circ} \mathrm{C}$.

Measurement valid for the second value of the diode's current is shown in Fig. 8, while $\mathrm{I}_{\mathrm{F}(\mathrm{RMS})}=410 \mathrm{~mA}$. The temperature distribution within the diode package is the same as for the previous situation, while the thermal maximum achieves $152{ }^{\circ} \mathrm{C}$.

Because the operational maximum of selected power diode, from the thermal performance point of view, is defined as $150{ }^{\circ} \mathrm{C}$, the last experiment was realized for $500 \mathrm{~mA}$. The temperature maximum is defined for the body of the diode, and therefore even temperature reached $152{ }^{\circ} \mathrm{C}$ within the previous experiment, it is seen that device temperature considering the whole volume is around $100{ }^{\circ} \mathrm{C}$. Figure 9 shows thermal distribution for $\operatorname{IF}(\mathrm{RMS})=500 \mathrm{~mA}$. The temperature of? hot spot reached over $180{ }^{\circ} \mathrm{C}$, and this point presents the maximum operational limit considering the temperature of the device.

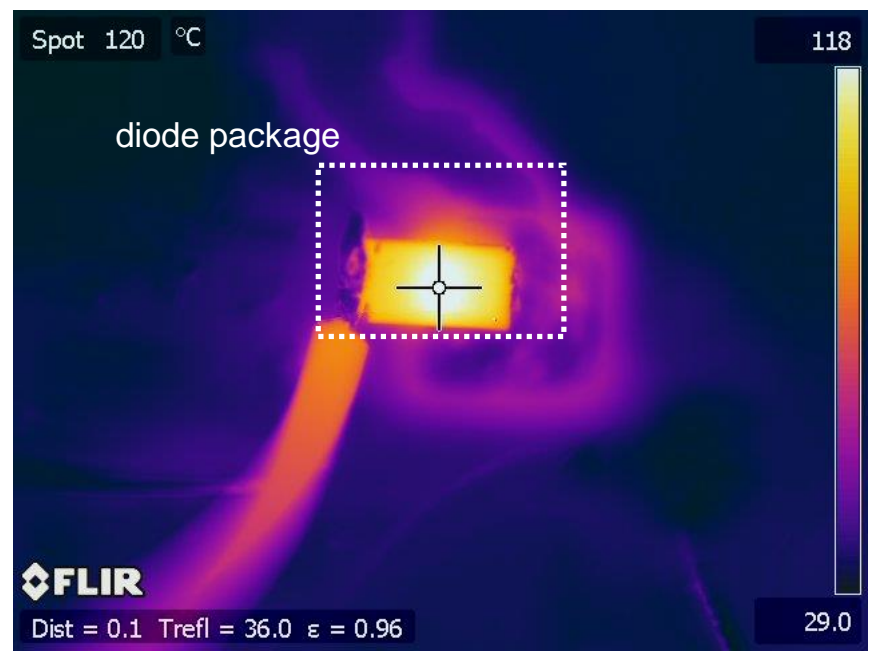

Fig. 7. The measured temperature for $300[\mathrm{~mA}]$ forward current.

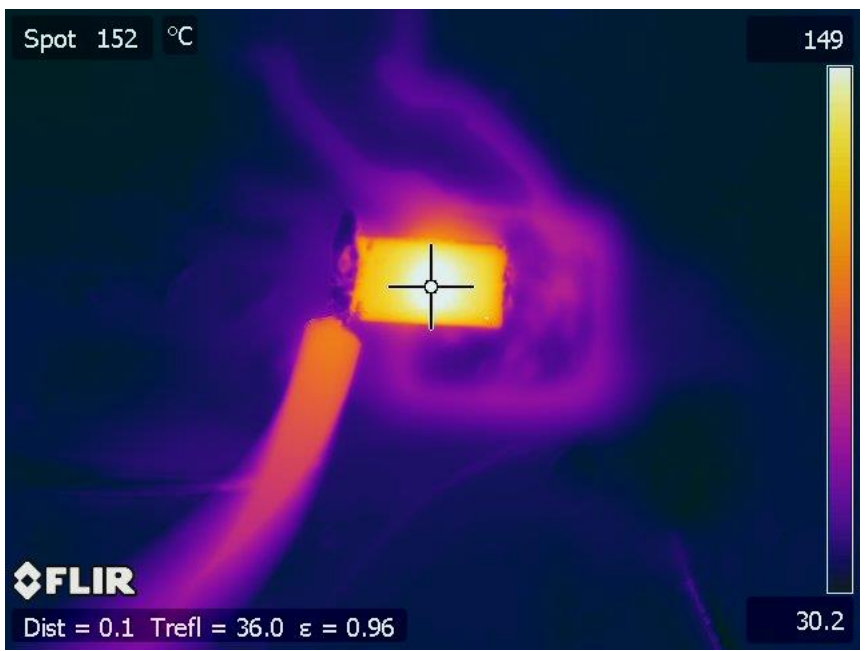

Fig. 8. The measured temperature for $410[\mathrm{~mA}]$ forward current.

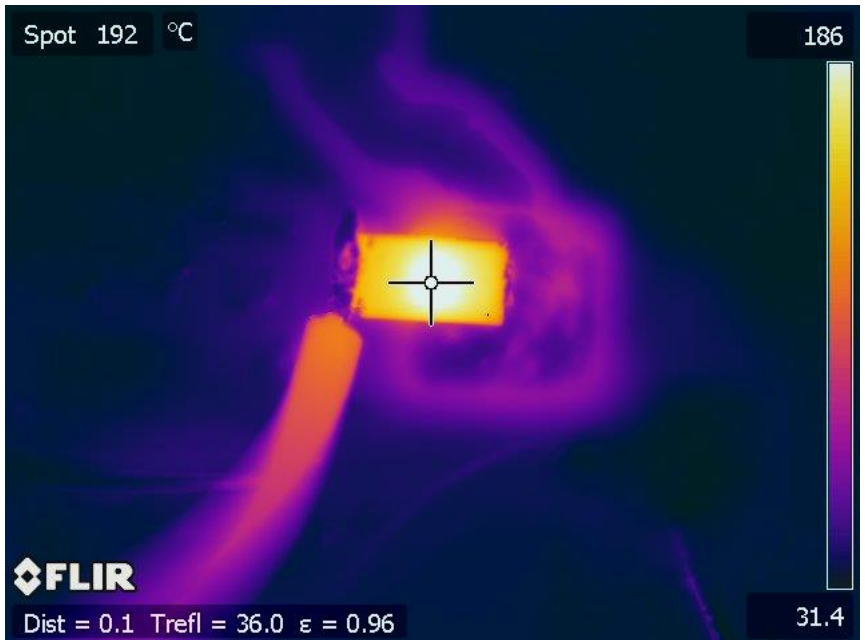

Fig. 9. The measured temperature for $500[\mathrm{~mA}]$ forward current.

After these experimental measurements, the validation of the simulation model was provided considering operational conditions defined within experiments. 


\section{Simulation Results}

The simulation results are compared with the measurement for three forward current values $(300 \mathrm{~mA}$, $410 \mathrm{~mA}$, and $500 \mathrm{~mA}$ ). The first comparison is for diode forward current $300 \mathrm{~mA}$, where the simulated maximal temperature of the diode package (Fig. 10-Fig. 12) has value of $116.5^{\circ} \mathrm{C}$ and the measured maximal temperature of the diode package is $120{ }^{\circ} \mathrm{C}$. The relative error between these temperature results is less than $3 \%$.

For the forward current value of $410 \mathrm{~mA}$, the measured temperature is $152{ }^{\circ} \mathrm{C}$ and the simulated temperature is $151^{\circ} \mathrm{C}$. The relative error, in this case, is less than $0.5 \%$.

For the forward current value of $500 \mathrm{~mA}$, the measured temperature is $192{ }^{\circ} \mathrm{C}$ and the simulated temperature is $180{ }^{\circ} \mathrm{C}$. The relative error, in this case, is less than $6.5 \%$.

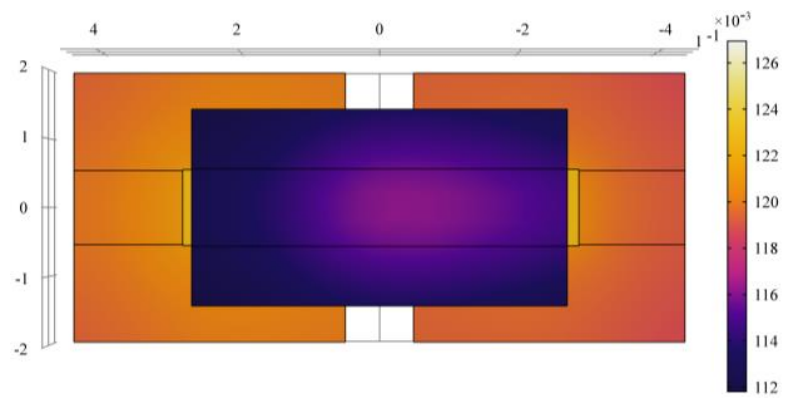

Fig. 10. Simulated temperature for 300 [mA] forward current.

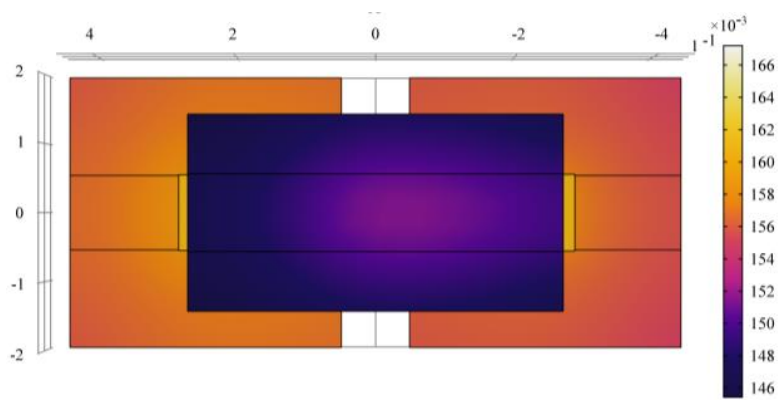

Fig. 11. Simulated temperature for 410 [mA] forward current.

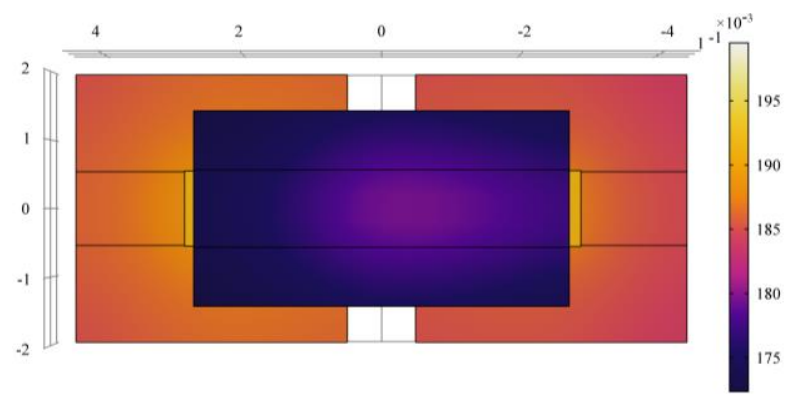

Fig. 12. Simulated temperature for $500[\mathrm{~mA}]$ forward current.

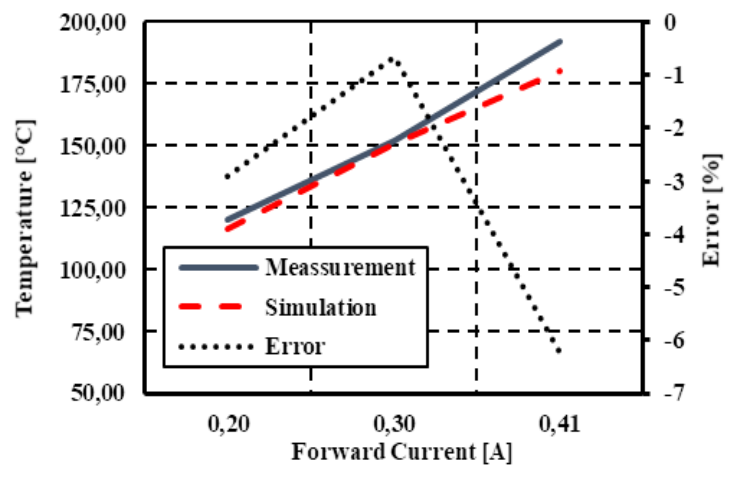

Fig. 13. The relative error of the proposed simulation model.
The graphical interpretation of the relative error of the proposed electro-thermal simulation model of the selected power diode in comparison to experimental measurement is shown on Fig. 13. As can be seen, the maximal error in temperature for given forward current range is lower than $6.5 \%$, while an increase of this error is significant for the higher values of the forward currents, i.e, above $450 \mathrm{~mA}$. The reason for the error increase lies probably at the undefined material properties change at the operational limits of the component.

\section{CONClusions}

The paper discussed the design procedure of the simulation model of power diode, whose properties are relevant for electro-thermal performance investigation. Initially, the geometrical model within CFD software (COMSOL) was realized. The definitions of the geometrical parameters given within the paper show how it is possible to prepare fully reconfigurable simulation model. Individual parameters of the geometrical part are then related to the physical properties of the model. After this, the identification of the parameters, which influence temperature performance of the component, i.e. it deals about physical variables like conductivities of individual component subdomains. The procedure of the parameter identifications is indirect, i.e. the designer does not need to receive material properties defined by the manufacturer [11]. The proposed methodology uses identification based on VA diode characteristic matching. The validation of the proposed model accuracy and validity was evaluated by the results received from the experimental measurement of thermal behaviour of the selected diode. The evaluation was based on an investigation of temperature distribution within the component surface for various operational conditions considering different power loading of the component. After evaluation, it was found that the relative error between results from simulation and measurements vary from $-0.5 \%$ to $-6.5 \%$ based on the amount of the forward current flowing through the diode. Increasing error reported at the end of the paper shall be caused by the unspecified structural component changes. Future works will be further focused on the optimization of the model accuracy considering the evaluation of the specific parameter properties based on the operational conditions of the investigated component.

\section{ACKNOWLEDGMENT}

Special thank is given to cooperation with BSH Drives and pumps Slovakia for coordination of individual research tasks.

\section{CONFLICTS OF INTEREST}

The authors declare that they have no conflicts of interest.

\section{REFERENCES}

[1] N. Vakrilov, A. Stoynova, and B. Bonev, "3D Thermal modelling and verification of power electronic modules", in Proc. of $201942^{\text {nd }}$ International Spring Seminar on Electronics Technology (ISSE), Wroclaw, Poland, 2019, pp. 1-4. DOI: 10.1109/ISSE.2019.8810307.

[2] M. Frivaldsky, P. Spanik, P. Drgona, and Z. Loncova, "Algorithms for indirect investigation of heat distribution in electronic systems", 
International Journal of Thermal Sciences, vol. 114, pp. 15-34. DOI: 10.1016/j.ijthermalsci.2016.12.005.

[3] P. Spanik, J. Cuntala, M. Frivaldsky, and P. Drgona, "Investigation of heat transfer of electronic system through utilization of novel computation algorithms", Elektronika Ir Elektrotechnika, vol. 123 no. 7, pp. 31-36. DOI: 10.5755/j01.eee.123.7.2371.

[4] P. Rafajdus, A. Peniak, P. Dubravka et al., "Optimization of switched reluctance motor design procedure for electrical vehicles", in Proc. of 2014 International Conference on Optimization of Electrical and Electronic Equipment (OPTIM), 2014. DOI: 10.1109/OPTIM.2014.6851033.

[5] V. Eveloy, J. Lohan, and P. Rodgers, "A benchmark study of computational fluid dynamics predictive accuracy for componentprinted circuit board heat transfer", IEEE transactions on components and packaging technologies, vol. 23, no. 3, pp. 568576, 2000. DOI: 10.1109/6144.868860.

[6] D. Tatchell, J. Parry, and I. Clark, "Advances in cooling electronics with CFD”, NAFEMS World Congress, June 10-12, 2013, Salzburg, Austria.

[7] R. Mashayekhi, E. Khodabandeh, O. A. Akbari et al., "CFD analysis of thermal and hydrodynamic characteristics of hybrid nanofluid in a new designed sinusoidal double-layered microchannel heat sink", $J$.
Therm. Anal. Calorim., vol. 134, pp. 2305-2315, 2018. DOI 10.1007/s10973-018-7671-3.

[8] K. Hruska, V. Kindl, and R. Pechanek, "Design and FEM analyses of an electrically excited automotive synchronous motor", in Proc. of 2012 15th International Power Electronics and Motion Control Conference (EPE/PEMC), Novi Sad, 2012, pp. LS2e.2-1-LS2e.2-7. DOI: 10.1109/EPEPEMC.2012.6397422.

[9] S. Kascak, M. Prazenica, M. Jarabicova, and M. Paskala, "Interleaved DC/DC boost converter with coupled inductors", Advances in Electrical and Electronic Engineering, vol. 16, no. 2, pp. 147-154, 2018. DOI: 10.15598/aeee.v16i2.2413.

[10] S. Kascak, M. Prazenica, M. Frivaldsky, M. Pavelek, and M. Jarabicova, "Investigation of thermal performance of magnetic components in interleaved DC/DC converters", in Proc. of 2018 ELEKTRO, Mikulov, Czech Republic, 2018, pp. 1-6. DOI: 10.1109/ELEKTRO.2018.8398270.

[11] M. Frivaldsky, T. Donic, V. Vavrus, and M. Pavelek, "Experimental research of optimization methodology for local, resistive - heating of thin molybdenum plates", International Journal of Thermal Sciences, vol. 121, pp. 111-123, 2017. DOI: 10.1016/j.ijthermalsci.2017.07.009. 